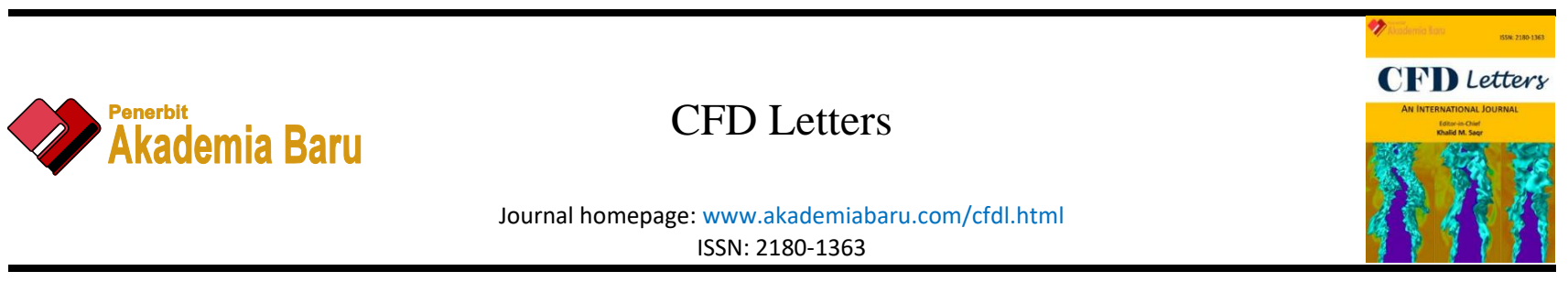

\title{
Potential of Utilizing Solar Chimney as an Energy Efficiency Measure in Malaysian Hospitals
}

\author{
Sheikh Saiful Azam Samsudin ${ }^{1}$, Abdul Muin Shaari ${ }^{1,}{ }^{*}$, Kamil Abdullah $^{1}$, Mohd Faizal Mohideen \\ Batcha $^{1}$
}

1 Department of Mechanical Engineering, Faculty of Mechanical Engineering and Manufacturing, Universiti Tun Hussein Onn Malaysia, 86400 Parit Raja, Johor, Malaysia

\section{ARTICLE INFO ABSTRACT}

\section{Article history:}

Received 20 February 2020

Received in revised form 18 April 2020

Accepted 22 April 2020

Available online 30 April 2020
Keywords:

ANSYS; hospital energy saving; solar chimney; tropical climate

\begin{abstract}
Many energy efficiency measures were proposed to reduce the high energy demand in hospitals. Solar chimney is a form of passive solar heating and cooling system that can be used for temperature regulation and ventilation of a building This paper explores the solar chimney's performance in terms of air changes per hour (ACH) in Malaysian tropical climate were thus, investigated for its feasibility in Malaysian hospitals. A 2D CFX model is simulated at four different times ( $8 \mathrm{am}, 10 \mathrm{am}, 2 \mathrm{pm}$ and $4 \mathrm{pm})$. Openings provided at the bottom and top of the chimney and at the right of the cabin with dimension of $1 \mathrm{~m}$ located $1 \mathrm{~m}$ from the floor level to allow air with room temperature to enter the cabin and towards the solar chimney. Simulations were validated form previous study and the study use solar irradiance from previous study to simulate Malaysia's solar irradiance and outside temperature. Steady state and laminar flow were used in this study to model air turbulence in the cabin to the solar chimney. The results show that the simulations have been validated and all 4 of different time have been simulated. $2 \mathrm{pm}$ with the highest solar irradiance have the most air changes per hour (ACH), while 8 am with the lowest solar irradiance have the least $\mathrm{ACH}$. Further experimental study is currently ongoing.
\end{abstract}

Copyright @ 2020 PENERBIT AKADEMIA BARU - All rights reserved

\section{Introduction}

Hospital is one of the longest energy consumers among buildings in Malaysia. This is due to the nature of operation: $24 / 7$, high occupancy and large equipment. The largest energy consumer is the air conditioning system with an estimated usage of $60 \%$ of total energy consumed. Hence, energy efficiency is crucial to ease the energy demand. In this study, potential of integration of solar chimney in hospital building is explored, emphasizing on its suitability in tropical climate such as Malaysia. Malaysia is located on the South China Sea, ranging from $3.164^{\circ}$ north latitude to $101.7^{\circ}$ east longitude. Because it lies completely in the equatorial zone, it has a warm and humid climate

\footnotetext{
* Corresponding author.

E-mail address: muinshaari@gmail.com (Abdul Muin Shaari)
} 
experience. The climate is governed by the northeastern monsoon regime, which begins from November to March and the southwestern monsoon originates from the Australian desert blow between May and mid-September. The ambient temperature ranges from $24^{\circ} \mathrm{C}$ to $33^{\circ} \mathrm{C}[1]$. The average solar radiation is about $4.5 \mathrm{kWh} / \mathrm{m}^{2}$ per day and $400-600 \mathrm{MJ} / \mathrm{m}^{2}$ per month [2]. The Klang Valley (Kuala Lumpur, Petaling Jaya) has the lowest solar radiation value in Peninsular Malaysia, whereas the highest values are measured around Bayan Lepas (Penang) [3].

A solar chimney attached to a building serves as an excellent ventilation strategy based on the natural driving force, that is, the Sun's energy. A study on the performance of two power output control schemes for power plants in the solar chimney shown that the optimum ratio is not constant throughout the day and depends on the coefficients of heat transfer applied to the collector [4]. In experiments on a construction roof at the University of Melbourne, Australia, with a modified Trombe wall by Akbarzadeh et al., [5] predicted the air velocity and temperature within a solar chimney using two-dimensional, incompressible and steady state FLUENT simulations with Boussinesq approximation. Various different turbulence models were examined and the realizable k$\varepsilon$ model was found to be the most suitable. Furthermore, simulated results predicted that increasing the outer wall temperature caused an increase in the volume flowrate and air temperature [6].

A study in the solar chimney has been observed for single-story residential buildings in Malaysia that an optimal width gap of $1 \mathrm{~m}$ is recommended for $3.5 \mathrm{~m}$ solar chimney height [7]. Under asymmetrical and symmetrical heating conditions of uniform wall temperature and uniform heat flux, study for both laminar and turbulent natural convection was made in a vertical open channel of solar chimney configuration. Their results showed that there was no simultaneous optimization of the dynamic (mass flow) and thermal (heat transfer) performance of a solar chimney system [8]. In other study concluded that increasing the width of the chimney from $0.1 \mathrm{~m}$ to $0.3 \mathrm{~m}$ improved the $\mathrm{ACH}$ by almost $25 \%$, keeping the size of the chimney inlet fixed [9]. They also found that the width of the chimney has a more significant effect on the pattern of space flow than the size of the chimney inlet. In study showed that the surface radiation changes the fields of flow and temperature, affects the Nusselt number and the volume flow rate and improves ventilation performance [10]. From numerous study solar chimney can reduce cooling load and improve natural ventilation [11-13].

Solar irradiance is the amount of solar radiant energy falling on a surface per unit area and time per unit. For most engineering applications, solar radiation measurements are one of the most important. It is used for solar energy application design, sizing performance assessment and research. Because this study is about feasibility of solar chimney in Malaysian hospitals only solar irradiance data in Malaysian climate is simulated in this study. The high potential of feasibility of solar chimney in Malaysian hospitals will benefit greatly in terms of energy efficiency. The main focus in this study is on the performance of the analysis of solar chimney in Malaysia by making air changes per hour $(\mathrm{ACH})$ the performance criteria and feasibility of a solar chimney in Malaysian hospitals.

\section{Methodology}

To investigate the proposed solar chimney as a tool for energy efficiency at hospitals, several parameters that affect the solar chimney's performance were considered based on the published literature. Solar irradiance is the most widely used and the most conclusive parameter of research. Researchers find that increasing solar irradiance increases air speed and temperature within the solar chimney. The results that were presented by Daut et al., [14] have been used for the study meanwhile for the validation, theoretical and experimental results in Bassiouny et al., [15] were used. After a good agreement between simulation with theoretical and simulation results the numerical setup from validation is used directly with only changing the solar irradiance and opening temperature. All 
4 of the solar irradiance at different time ( $8 \mathrm{am}, 10 \mathrm{am}, 2 \mathrm{pm}, 4 \mathrm{pm})$ were simulated and ACH is analyzed. The choice of timing is based on the ambient temperature, which influences the air density and hence the buoyancy force which creates the natural convection current in the solar chimney.

\subsection{Computational Domain}

CFX is chosen as the computational software to simulate the physical model as it is widely used internationally by researchers in the field of solar chimney research. The computational model is developed by ignoring the roof above of the cabin. Figure 1 and Figure 2 shows the typical solar chimney design used in buildings, as well as the computational domain with a thickness of $10 \mathrm{~mm}$.

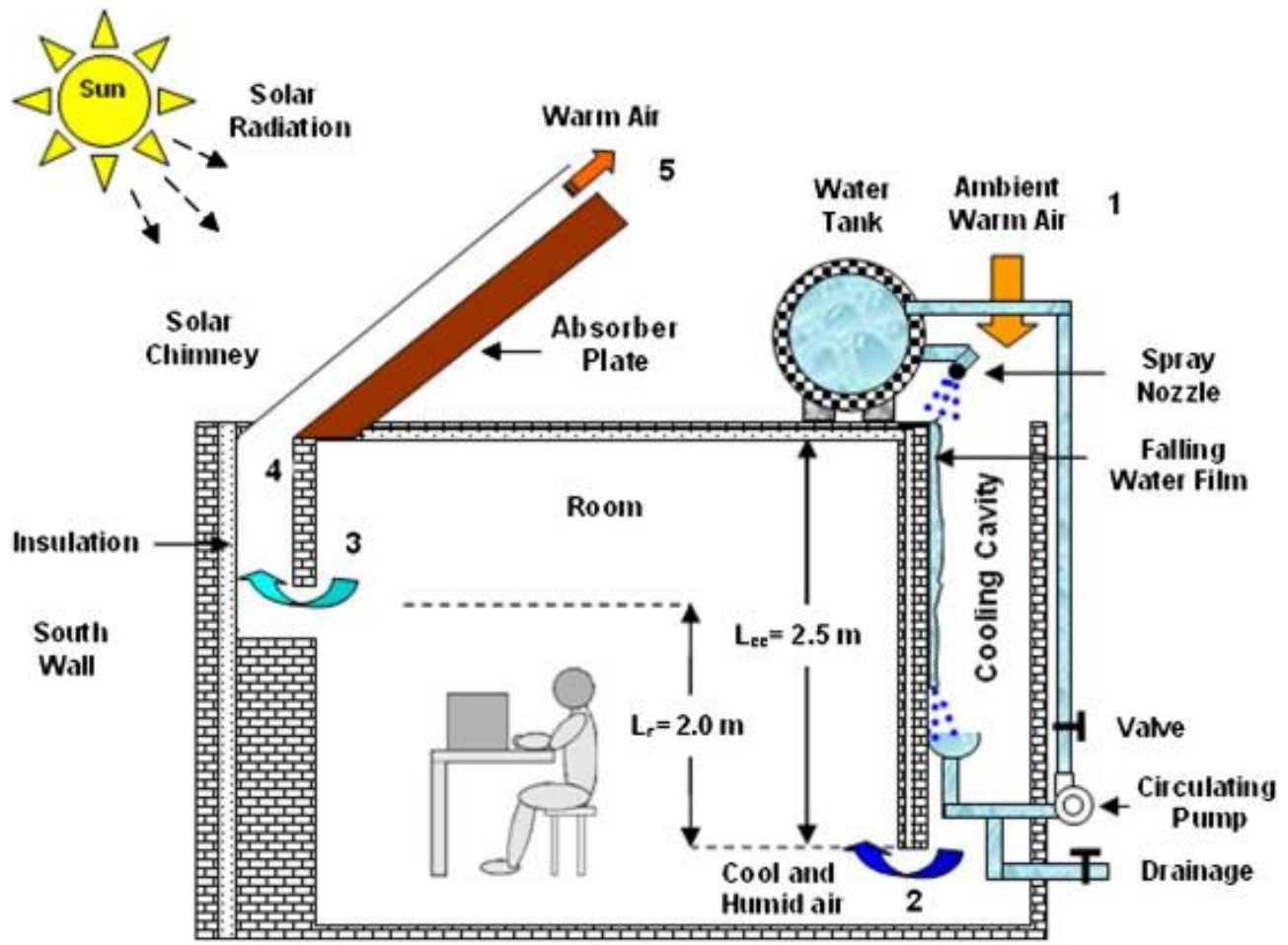

Fig. 1. A typical inclined solar chimney cabin [16]

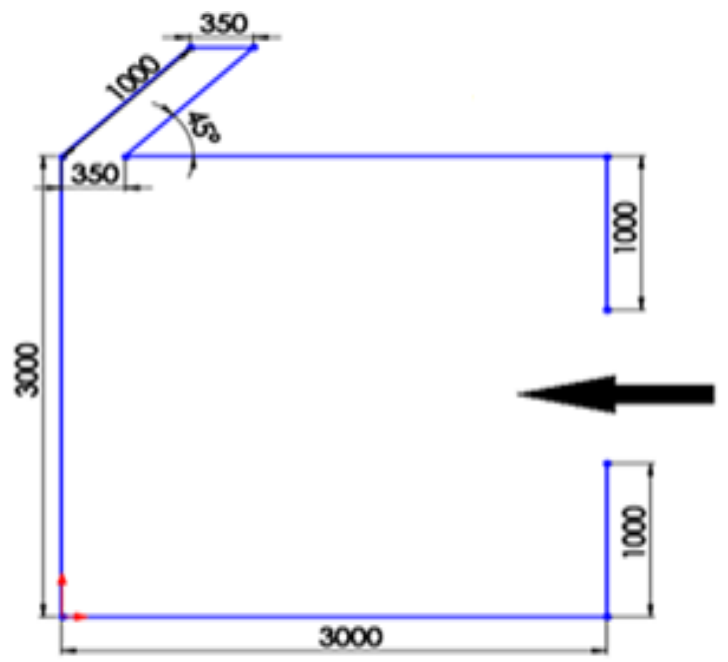

Fig. 2. Solar chimney dimension 
The modeled domain contains only the fluid domain as the material, which is air at $25^{\circ} \mathrm{C}$. The air reference pressure is $1 \mathrm{~atm}$. The air leaves through the solar chimney and enters the open window. The buoyancy model is turned on at $25^{\circ} \mathrm{C}$ and at y-direction the gravity is applied. With thermal energy and thermal radiation activated, the airflow within the domain is considered laminar.

\subsection{Computational Setup}

Figure 3 and Table 1 show the setup needed to simulate this study. Firstly, to simulate 2D CFX front and back of the model must be put in symmetry boundary condition. All wall boundary condition must be no-slip wall condition. There are two openings where atmospheric pressure is considered. There are openings on the right that lead the air to the solar chimney and on the left to the outside air at the solar chimney. The solar chimney is glazed and fitted with an absorber. To avoid conjugate heat transfer problem, the boundary condition for the glazing and absorber are calculated manually from the value at Table 2.

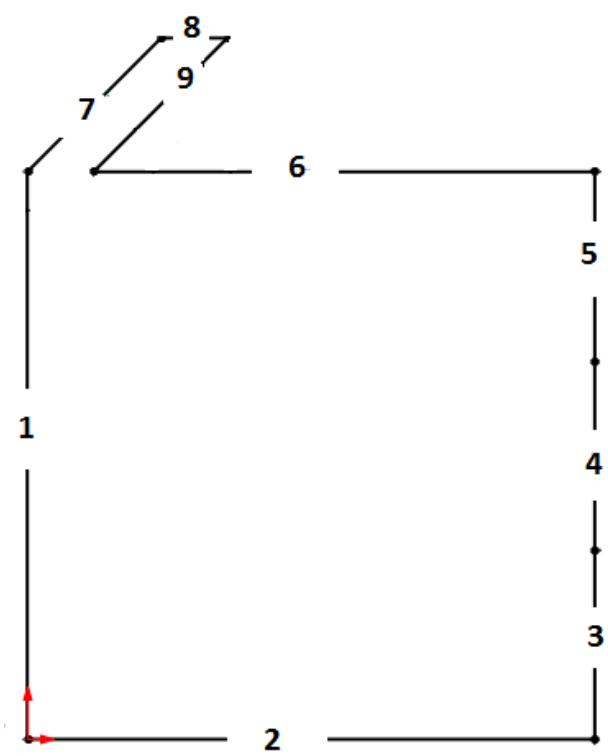

Fig. 3. Location for boundary condition

Table 1

Specification for boundary condition

\begin{tabular}{lll}
\hline Location & Surface Name & Boundary Condition \\
\hline $1,2,3,5,6$ & Wall & Wall (Room Temperature) \\
4 & Window & Opening (Room Temperature) \\
7 & Glazing & Glass Heat Flux (0.9 emissivity) \\
8 & Chimney & Opening (Outlet Temperature) \\
9 & Absorber & Absorber Heat Flux (0.95 emissivity) \\
\hline
\end{tabular}

Table 2

Variation of solar irradiance and outside temperature according time

\begin{tabular}{lll}
\hline Time & Solar Irradiance $\left(\mathrm{W} / \mathrm{m}^{2}\right)$ & Outside Temperature $\left({ }^{\circ} \mathrm{C}\right)$ \\
\hline $8 \mathrm{am}$ & 100 & 25 \\
$10 \mathrm{am}$ & 420 & 29 \\
$2 \mathrm{pm}$ & 720 & 33 \\
$4 \mathrm{pm}$ & 500 & 30 \\
\hline
\end{tabular}


To simulate 2D CFX the mesh size is the same as model thickness $(10 \mathrm{~mm})$ and simulated up to 6000 iterations with residual target of 0.0001 or whichever comes first.

\subsection{Performance Criteria: ACH (Air Changes Per Hour)}

Air changes per hour, ACPH or ACH abbreviated or air change rate is a measure of the volume of air added to or removed from a space (normally a room or house) divided by the volume of space. If the air in the space is either uniform or perfectly mixed, changes in air per hour are a measure of how many times the air is replaced within a defined space. Air is neither uniform nor perfectly mixed in many air distribution arrangements. The actual percentage of the air exchanged within a period of an enclosure depends on the enclosure's airflow efficiency and the methods used to ventilate it.

$\mathrm{ACH}$ is formulated by

$A C H=\frac{60 Q}{V}$

where $Q$ is volumetric flow rate (cubic meter per minute) and $V$ is volume of the room (cubic meter)

\subsection{Validation}

The validation of the present numerical model is carried out by comparing the numerical results with the experimental results of previous study obtained for a $3 \mathrm{~m}$ height and $3 \mathrm{~m}$ width cabin with 45 inclined channel of solar chimney. Simulations are carried out for the heat flux over the range of 650,700 and $750 \mathrm{~W} / \mathrm{m}^{2}$ with its own outside temperature. Figure 4 and Figure 5 compares the results between the mean air velocities at the channel exit and mass flow rate numerically predicted and experimentally measured, showing a good agreement between the experiment and simulation. Table 3 shows the grid independence study.

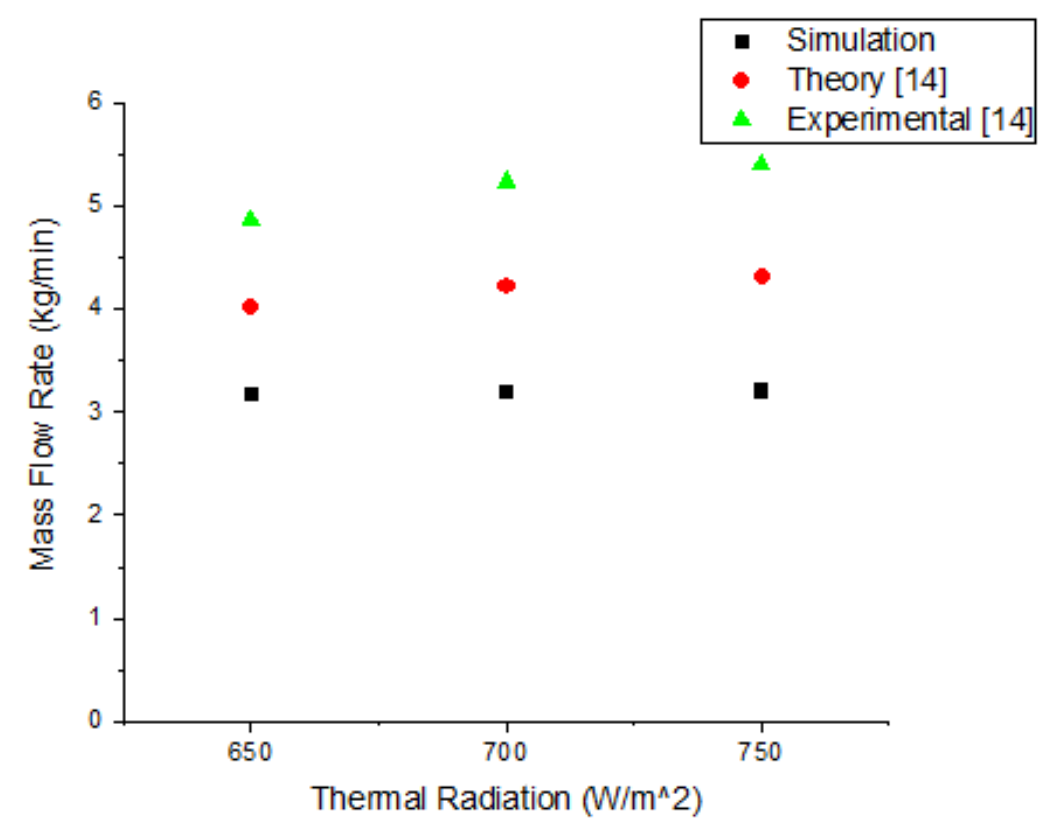

Fig. 4. Mass flow rate 


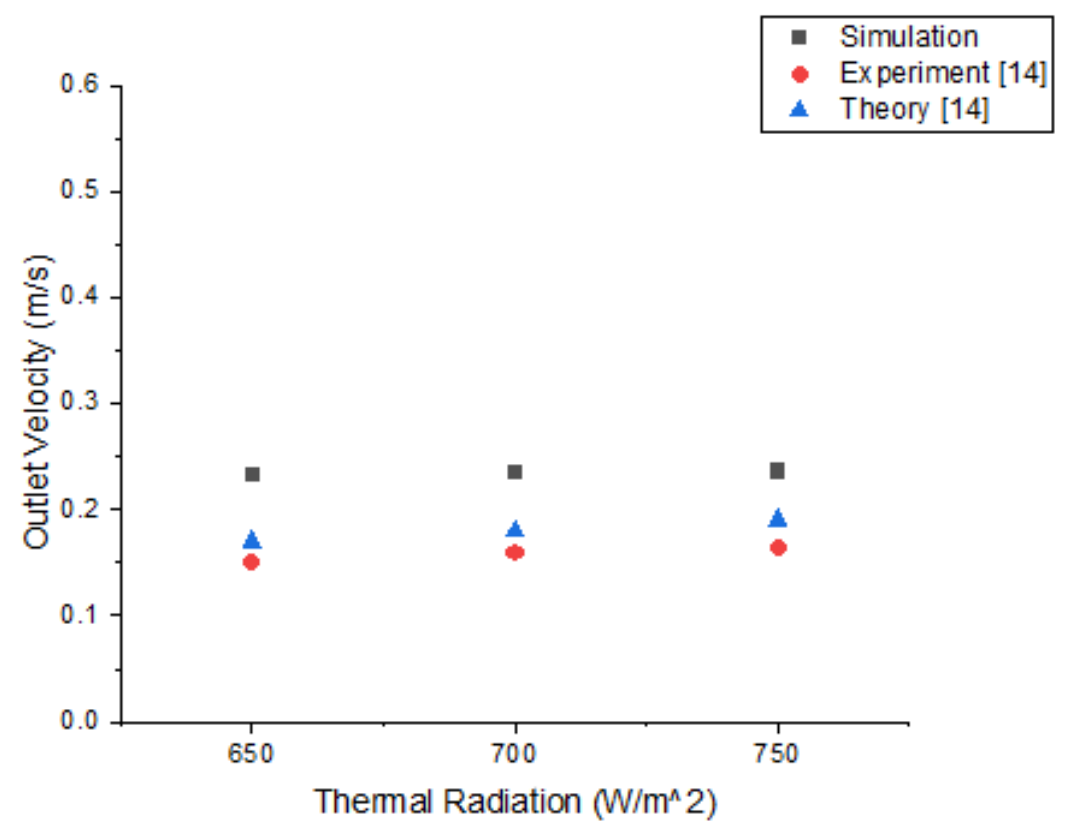

Fig. 5. Outlet velocity

Table 3

Grid independence study

\begin{tabular}{lll}
\hline Mesh size $(\mathrm{m})$ & Outlet Velocity $\left(\mathrm{ms}^{-1}\right)$ & Time taken for 6000 iterations \\
\hline 0.1 & 0.35 & 1 hour \\
0.075 & 0.22 & 2 hours 15 minutes \\
0.05 & 0.155 & 3 hours \\
0.025 & 0.152 & 5 hours 30 minutes \\
0.01 & 0.15 & 10 hours 45 minutes \\
\hline
\end{tabular}

\section{Results and Discussion}

The simulation results of this study will be discussed in terms of velocity contour, vorticity contour, vector plot, velocity profile and changes in air per hour. The results will provide physical description of the flow phenomenon inside the solar chimney and its expected adjoining space.

\subsection{Velocity Contour}

Figure 6 shows the contour of the $u$ velocity part of four configurations considered for the solar chimney. The velocity contours were plotted in the range of $-0.20485 \mathrm{~m} / \mathrm{s}$ to $0.286 \mathrm{~m} / \mathrm{s}$ and the positive flow direction is set to the right side of the computational models. In general, the aspect of high u velocity can be observed for all cases at the solar chimney region, supporting the existence of the buoyancy effect due to the flux of surface heat. Lower element of the u velocity can be observed in the cabin area. At $2 \mathrm{pm}$, a strong negative element of $u$ velocity can be seen entering the cabin area from the window. The relative high value of the $u$ velocity element indicates good external air penetration into the cabin area. Reduction of the penetration can be observed as the solar irradiance reduces at $4 \mathrm{pm}, 10 \mathrm{am}$ and $8 \mathrm{am}$. Figure 5 also shows that the top right and bottom of the cabin are subject to very low positive u velocity, indicating rotational flow occurrence in the respective region. The concept will be explored further in the next section of this study. 


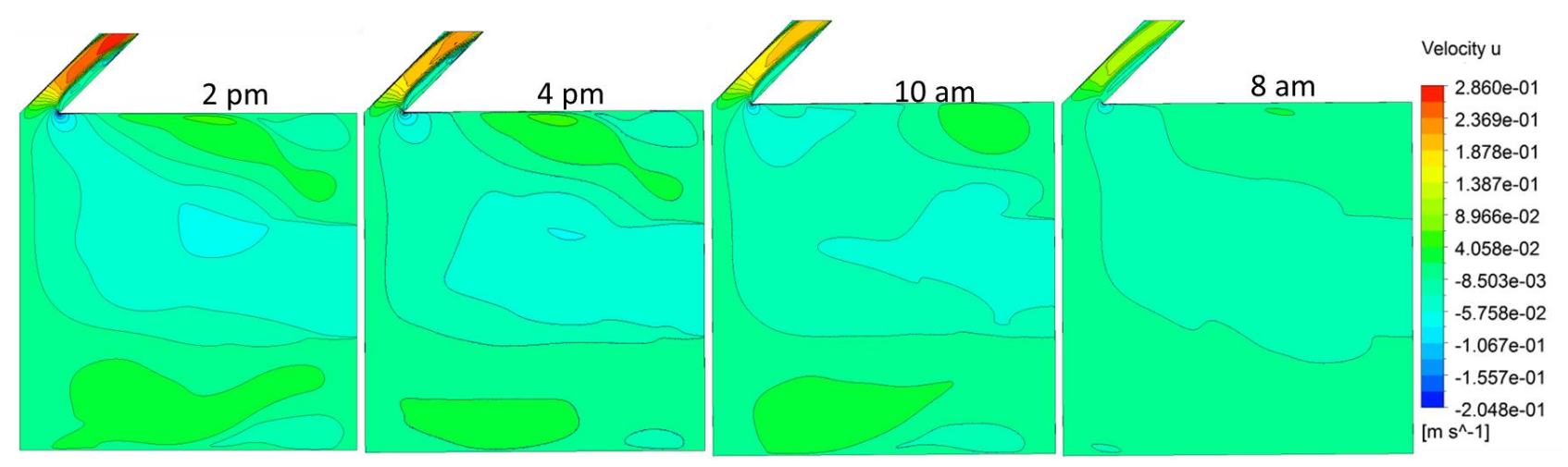

Fig. 6. Velocity Contour at corresponding time

\subsection{Velocity Vector and Vorticity Contour}

Figure 7 displays the contour of vorticity and the vector plot for each configuration of the solar chimney considered in this analysis. The findings were intended to address the potential incidence of rotational flow, as indicated in the previous section. The vorticity contour was set to the range between $0 \mathrm{~s}^{-1}$ and $1 \mathrm{~s}^{-1}$ while the vector represented total magnitude of the velocity within the computational domain. Vorticity is mathematically defined as the curl of the field of velocity, and is therefore a measure of the local rotation of the fluid. The description makes it a vector quantity. Higher value of vorticity suggests rising wind speed when moving away from the trough center point and vice versa. In general, the vorticity in the top right and bottom of the cabin can be observed strong.

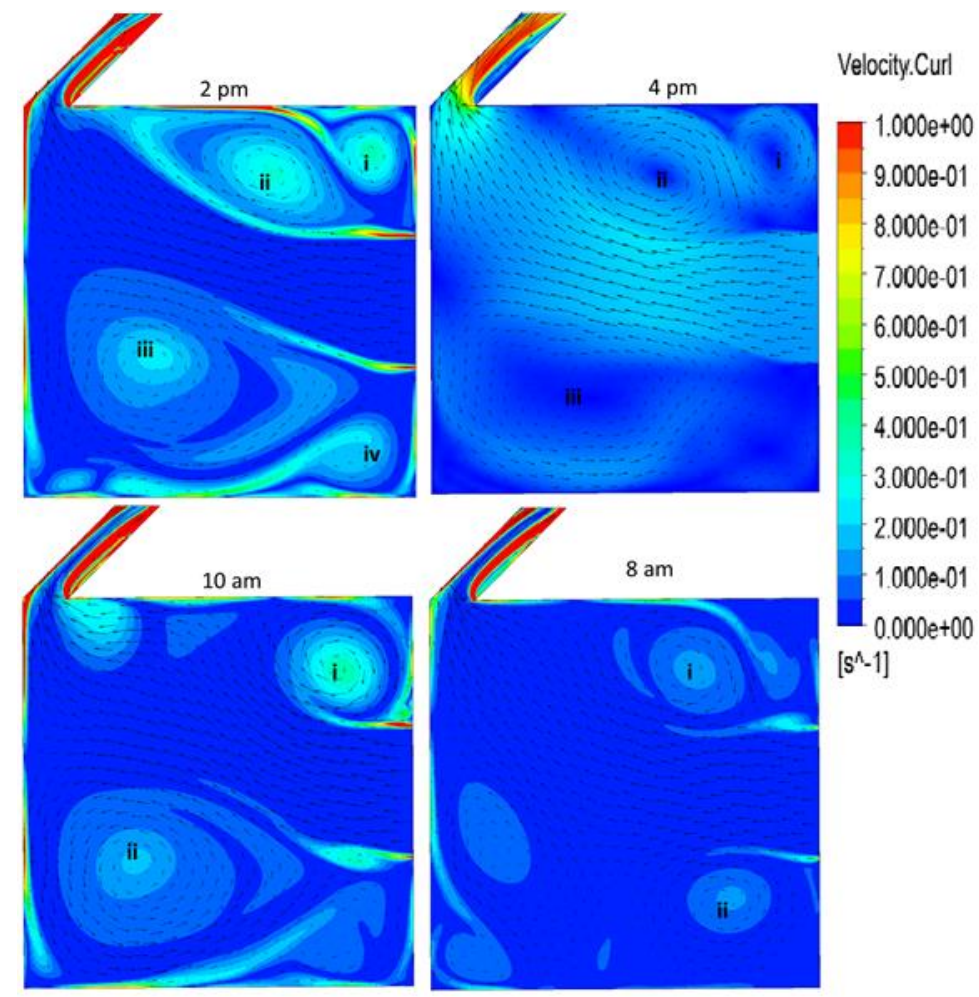

Fig. 7. Swirl point for each time

Swirl points can be decided by visibility both of velocity curl contour and velocity vector The number of swirl or vorticity core points can be found to be minimum in in at $8 \mathrm{am}, 10 \mathrm{am}$ and $4 \mathrm{pm}$ 
with two points and maximum at $2 \mathrm{pm}$ at four points. In Figure 6 all of the swirl points were labelled. At 2 p.m., the cabin's top right region was dominated by the rotational flow originating at the point labeled as I while the lower region is dominated by two distinct rotational flows originating at points labeled as iii and iv. The occurrence of the rotational flow is induced by the main air flow path from the window to the solar chimney which causes the air in the areas to stay in the cabin area continuously. As the air penetration from the window at 8 am becomes lower, the decrease in rotational flow also becomes relatively more noticeable. Existence of 2 weak swirl points in the cabin area at 8 am supported it. $4 \mathrm{pm}$ can be observed have a steady flow compared to other time even though it has 3 swirl points. This is because of the moderate solar irradiance and high temperature.

The low vorticity value observed in the area at the bottom of the cabin indicates weaker air flow in the area. The vector plots shown in Figure 6 are consistent with the discussion on flow penetration from the window into the cabin region in the previous section.

\subsection{Velocity Profile}

Figure 8 displays the velocity profile for all configurations that was recorded at the solar chimney outlet. Maximum 20 points were extracted and mapped to represent the velocity profile. To compare it with all cases, at $2 \mathrm{pm}$ registered highest average exit velocity at $0.2404 \mathrm{~m} / \mathrm{s}$ while at 8 am registered the lowest average exit velocity at $0.0813 \mathrm{~m} / \mathrm{s}$. At lower solar irradiance, the velocity distribution is observed to be lower. This is because by the higher solar irradiance, fluid domain move faster towards exiting chimney as can be noticed in Figure 7.

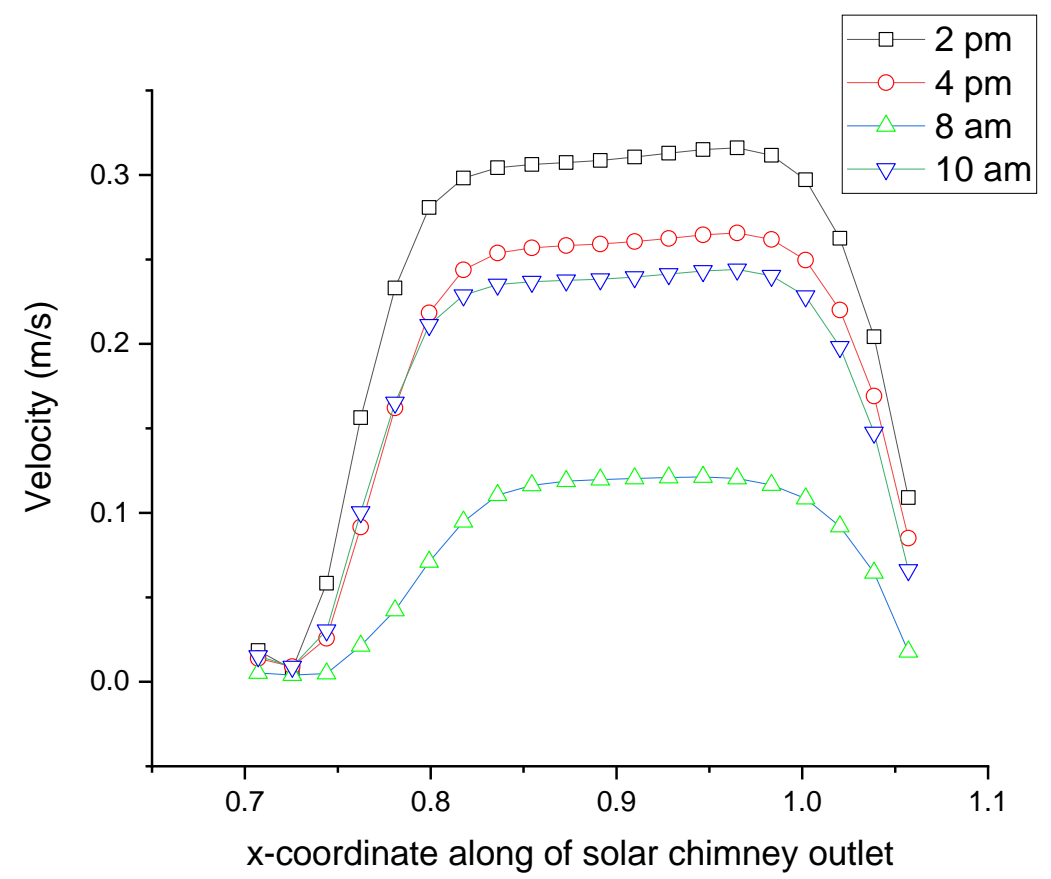

Fig. 8. Outlet Velocity

\subsection{Air Changes Per Hour (ACH)}

Increased solar irradiance greatly increases outlet velocity. This can be said because of the higher solar irradiance made the fluid domain move faster. All time have a very similar pattern and the velocity profile ended differently for each time. High solar irradiance corresponds with higher mass flow rate and higher $\mathrm{ACH}$. 
From window to solar chimney airflow perspective, $2 \mathrm{pm}$ with the highest velocity of air while 8 am with the lowest velocity of air were further proven in the Table 4 below that at $2 \mathrm{pm}$ have the highest of air changes per hour (ACH) while 8 am is the lowest. In terms of mass flow rate and air change per hour $(\mathrm{ACH})$, the low speed inside the cabin for 8 am can be seen its effect clearly. The $\mathrm{ACH}$ is measured and tabulated using the air properties at $25^{\circ} \mathrm{C}$.

Table 4

\begin{tabular}{lll}
\multicolumn{3}{l}{ Mass Flow Rate and ACH for each time } \\
\hline Time & Mass Flow Rate $(\mathrm{kg} / \mathrm{s})$ & $\mathrm{ACH}$ \\
\hline $2 \mathrm{pm}$ & 0.0539342 & 17.73 \\
$4 \mathrm{pm}$ & 0.0450978 & 14.83 \\
$10 \mathrm{am}$ & 0.043345 & 14.25 \\
$8 \mathrm{am}$ & 0.0206523 & 6.79 \\
\hline
\end{tabular}

The $\mathrm{ACH}$ reduction can be seen clearly when 10 am and 8 am compared. For all the time the reversed flow does not happen. A similar flow patterns can be seen in each simulation from windows opening to solar chimney. Even tough from previous study stated that simply increasing air change rates in the tested hospital operating rooms did not necessarily provide a cleaner general atmosphere, but significantly increased energy consumption and expenses [17] it can be neglected because solar chimney is a natural passive ventilation and can reduce cooling load [11].

\section{Conclusions}

This study explores the potential for energy efficiency in hospitals via integration with solar chimney. In this study, the effect of solar chimney has been the main focus of the study. From the CFD simulation, it was found that by differentiating the four input parameters and developing the computational models all simulations indicate that the temperature of the output air remains constant. This study was limited by the design of the solar chimney that have different orientation and different type of materials of the solar chimney may or may not change the performance of the solar chimney. From results of simulation it can be concluded that

i. Because of its highest solar irradiance $2 \mathrm{pm}$ produce the highest outlet velocity and $\mathrm{ACH}$.

ii. Lowest vorticity occur when highest solar irradiance is applied.

iii. A passive cooling solar chimney is feasible at hospital in Malaysia.

\section{Acknowledgement}

The authors would like to thank both Universiti Tun Hussein Onn Malaysia (UTHM) and Ministry of Education of Malaysia for the financial support through a GPPS grant (H039).

\section{References}

[1] Othman, Mohd Yusof Hj, Kamaruzzaman Sopian, Baharudin Yatim, and Mohd Noh Dalimin. "Diurnal pattern of global solar radiation in the tropics: a case study in Malaysia." Renewable Energy 3, no. 6-7 (1993): 741-745. https://doi.org/10.1016/0960-1481(93)90081-Q

[2] Mekhilef, Saad, Azadeh Safari, W. E. S. Mustaffa, Rahman Saidur, Rosli Omar, and M. A. A. Younis. "Solar energy in Malaysia: Current state and prospects." Renewable and Sustainable Energy Reviews 16, no. 1 (2012): 386-396. https://doi.org/10.1016/j.rser.2011.08.003

[3] Johari, A., S. Siti Hafshar, M. Ramli, and H. Hashim. "Potential use of solar photovoltaic in Peninsular Malaysia." In 2011 IEEE Conference on Clean Energy and Technology (CET), pp. 110-114. IEEE, 2011. https://doi.org/10.1109/CET.2011.6041446

[4] dos Santos Bernardes, Marco Aurelio, Ramon Molina Valle, and Márcio Fonte-Boa Cortez. "Numerical analysis of 
natural laminar convection in a radial solar heater." International journal of thermal sciences 38, no. 1 (1999): 4250 . https://doi.org/10.1016/S0035-3159(99)80015-4

[5] Akbarzadeh, A., W. W. S. Charters, and D. A. Lesslie. "Thermocirculation characteristics of a Trombe wall passive test cell." Solar Energy 28, no. 6 (1982): 461-468. https://doi.org/10.1016/0038-092X(82)90317-6

[6] Bacharoudis, Evangellos, Michalis Gr Vrachopoulos, Maria K. Koukou, Dionysios Margaris, Andronikos E. Filios, and Stamatis A. Mavrommatis. "Study of the natural convection phenomena inside a wall solar chimney with one wall adiabatic and one wall under a heat flux." Applied Thermal Engineering 27, no. 13 (2007): 2266-2275. https://doi.org/10.1016/i.applthermaleng.2007.01.021

[7] Nugroho, Agung Murti. "Solar chimney geometry for stack ventilation in Malaysia terrace house." PhD diss., Universiti Teknologi Malaysia, 2007.

[8] Zamora, B., and A. S. Kaiser. "Optimum wall-to-wall spacing in solar chimney shaped channels in natural convection by numerical investigation." Applied Thermal Engineering 29, no. 4 (2009): 762-769. https://doi.org/10.1016/i.applthermaleng.2008.04.010

[9] Bassiouny, Ramadan, and Nader SA Koura. "An analytical and numerical study of solar chimney use for room natural ventilation." Energy and buildings 40, no. 5 (2008): 865-873.

https://doi.org/10.1016/j.enbuild.2007.06.005

[10] Nouanégué, H. F., and E. Bilgen. "Heat transfer by convection, conduction and radiation in solar chimney systems for ventilation of dwellings." International Journal of Heat and Fluid Flow 30, no. 1 (2009): 150-157. https://doi.org/10.1016/j.ijheatfluidflow.2008.08.006

[11] Nugroho, Agung Murti, and Mohd Hamdan Ahmad. "Passive cooling performance of a solar chimney and vertical landscape applications in indonesian terraced house." Jurnal Teknologi 70, no. 7 (2014). https://doi.org/10.11113/jt.v70.3585

[12] Sung, Uk Joo, Soo Cho, Dong Hyun Seo, and Kyoo Dong Song. "Analysis of Reduced Cooling Load for a MultistoreyBuilding Incorporating a Ventilated Double Skin Façade with a Solar Chimney Channel." International Journal of Ventilation 11, no. 4 (2013): 381-391. https://doi.org/10.1080/14733315.2013.11683995

[13] Kamar, Haslinda Mohamed, Nazri Kamsah, and J. L. Kam. "Indoor air of a double-storey residential house in Malaysia." Journal of Advanced Research in Fluid Mechanics and Thermal Sciences 31, no. 1 (2017): 11-18.

[14] Daut, I., Farhana Zainuddin, Y. M. Irwan, and A. R. N. Razliana. "Analysis of solar irradiance and solar energy in Perlis, Northern of Peninsular Malaysia." Energy Procedia 18 (2012): 1421-1427. https://doi.org/10.1016/i.egypro.2012.05.158

[15] Bassiouny, Ramadan, and Nader SA Korah. "Effect of solar chimney inclination angle on space flow pattern and ventilation rate." Energy and Buildings 41, no. 2 (2009): 190-196. https://doi.org/10.1016/j.enbuild.2008.08.009

[16] Maerefat, M., and A. P. Haghighi. "Natural cooling of stand-alone houses using solar chimney and evaporative cooling cavity." Renewable Energy 35, no. 9 (2010): 2040-2052.

https://doi.org/10.1016/j.renene.2010.02.005

[17] Gormley, Thomas, Troy A. Markel, Howard Jones, Damon Greeley, John Ostojic, James H. Clarke, Mark Abkowitz, and Jennifer Wagner. "Cost-benefit analysis of different air change rates in an operating room environment." American journal of infection control 45, no. 12 (2017): 1318-1323. https://doi.org/10.1016/i.ajic.2017.07.024 